\title{
Involvement of HIF-1 $\alpha$ activation in the doxorubicin resistance of human osteosarcoma cells
}

\author{
LAURA RONCUZZI $^{1}$, FABIA PANCOTTI $^{1}$ and NICOLA BALDINI ${ }^{1,2}$ \\ ${ }^{1}$ Laboratory for Orthopaedic Pathophysiology and Regenerative Medicine, Istituto Ortopedico Rizzoli, I-40136 Bologna; \\ ${ }^{2}$ Department of Biomedical and Neuromotor Sciences, University of Bologna, I-40123 Bologna, Italy
}

Received December 6, 2013; Accepted February 3, 2014

DOI: $10.3892 /$ or.2014.3181

\begin{abstract}
Osteosarcoma is the most common primary bone cancer in children and adolescents. Despite aggressive treatment regimens, survival outcomes remain unsatisfactory, particularly in patients with metastatic and/or recurrent disease. Unfortunately, treatment failure is commonly due to the development of chemoresistance, for which the underlying molecular mechanisms remain unclear. The aim of the present study was to investigate the role of hypoxia-inducible factor $1 \alpha(\mathrm{HIF}-1 \alpha)$ and its signalling pathways as mediators of drug-resistance in human osteosarcoma. Toward this aim, we established two osteosarcoma cell lines selected for resistance to doxorubicin, a drug of choice in the treatment of this tumour. Our results showed that the multidrug resistance (MDR) phenotype was also mediated by HIF-1 $\alpha$, the most important regulator of cell adaptation to hypoxia. Our data showed that this transcription factor promoted the outward transport of intracellular doxorubicin by activating the P-glycoprotein (P-gp) expression in osteosarcoma cells maintained in normoxic conditions. In addition, it hindered doxorubicin-induced apoptosis by regulating the expression of c-Myc and p21. Finally, we observed that the doxorubicinresistant cells maintained for 2 months of continuous culture in a drug-free medium, lost their drug-resistance and this effect was associated with the absence of HIF-1 $\alpha$ expression. The emerging role of HIF-1 $\alpha$ in osteosarcoma biology indicates its use as a valuable therapeutic target.
\end{abstract}

\section{Introduction}

Osteosarcoma (OS) is the most common non-haematological primary malignant bone tumour in children and young adults (1). Although neoadjuvant chemotherapy and improved surgical technology have increased the survival rate to $65-75 \%$

Correspondence to: Dr Laura Roncuzzi, Laboratory for Orthopaedic Pathophysiology and Regenerative Medicine, Istituto Ortopedico Rizzoli, Via di Barbiano 1/10, I-40136 Bologna, Italy

E-mail: laura.roncuzzi@ior.it

Key words: doxorubicin, multidrug resistance, osteosarcoma, hypoxia-inducible factor-1 $\alpha, \mathrm{P}$-glycoprotein
(2), this combined treatment is still unsuccessful in $30-40 \%$ of patients with localised tumours and in $80-85 \%$ of patients with metastatic disease at presentation $(3,4)$. Multidrug resistance (MDR), both intrinsic and acquired, is still a major concern regarding the clinical management of osteosarcoma patients and a key issue in the failure of current treatment $(5,6)$. The development of an MDR phenotype can be mediated by several mechanisms, including energy-dependent efflux of chemotherapeutic drugs (7). The principal transmembrane transporter responsible for this mechanism is P-glycoprotein (P-gp), a drug efflux pump belonging to the ATP-binding cassette (ABC) protein superfamily, encoded by the multidrug resistance gene (MDR-1), which lowers intracellular drug concentrations to sub-lethal levels $(8,9)$. Although P-gp appears to be involved in resistance or a poor response to chemotherapy (10), other undefined cellular factors also seem to participate in modulating drug cytotoxicity in osteosarcoma cells. Thus, the analysis of the molecular mechanisms underlying the resistance of osteosarcoma cells to chemotherapy is essential for the development of novel treatment strategies for this disease.

A growing body of evidence has demonstrated that the microenvironment of the host has an important effect on the MDR of tumours, including $\mathrm{pH}$, temperature, partial pressure of oxygen nutrition and extracellular matrix components (11-14). In particular, there is a general consensus that hypoxia dramatically decreases the chemosensitivity of tumour cells promoting drug resistance to anticancer agents in a large variety of neoplasias $(15,16)$. A series of events occur during the adaptation of a tumour to hypoxia through a group of hypoxia-inducible factors (HIFs), of which HIF-1 $\alpha$ appears to be the most important in many different systems $(17,18)$. This is an heterodimeric protein that consists of a highly regulated HIF-1 $\alpha$ subunit and a constitutively expressed HIF-1 $\beta$ subunit (19). HIF-1 $\alpha$ is a transcription factor which permits hypoxic tumour cells to upregulate proteins that promote their survival and increase their aggressiveness. When adequate oxygen $\left(\mathrm{O}_{2}\right)$ is present, the subunit HIF-1 $\alpha$ becomes hydroxylated at several proline residues and this leads to ubiquitination and proteasomal degradation. However, when $\mathrm{O}_{2}$ is absent, this molecule survives and translocates to the nucleus, where it forms a heterodimer with HIF-1 $\beta$ (20). This dimer then binds to highly conserved hypoxia-response elements (HREs) within promoters of hypoxia-responsive genes inducing their 
transcription (21). Genes containing functional HREs encode proteins involved in angiogenesis (VEGF, endothelin-1), maturation of red blood cells (erythropoietin, transferrin), energy metabolism (glucose transporter 1 and 3), and cell proliferation and viability (insulin-like growth factor 2, p21) (18). Notably, it has been well documented that the MDR-1 gene, which encodes for P-glycoprotein, harbours different HREs which are HIF-1 $\alpha$ inducible (22). The drug resistance induced by HIF-1 $\alpha$-mediated P-gp expression has been observed in a plethora of tumour cells including glioma, breast carcinoma, gastric cancer and colon cancer cells (23-26).

The aim of the present study was to investigate the role of HIF- $1 \alpha$ and its signalling pathways underlying drug resistance in human osteosarcoma. For this purpose we generated and characterised two drug-resistant osteosarcoma cell lines selected for resistance to doxorubicin, a drug of choice in the treatment of this tumour. Our data showed that the MDR phenotype in human osteosarcoma cells was mediated by HIF-1 $\alpha$. A new potential model of chemo-resistance in human osteosarcoma including target genes of the non-canonical pathway of HIF-1 $\alpha$ is proposed.

\section{Materials and methods}

Drug. Doxorubicin (DXR) was purchased from Sigma-Aldrich (Milan, Italy). It was prepared as a $5 \mathrm{mg} / \mathrm{ml}$ fresh stock solution in phosphate-buffered saline (PBS) and was stored at $-20^{\circ} \mathrm{C}$. The drug was subsequently freshly diluted to the appropriate concentration in the culture medium before each experiment.

Cell culture. The human osteosarcoma cell line MG-63 was obtained from the American Type Culture Collection (ATCC; Manassas, VA, USA) and grown in Iscove's modified Dulbecco's medium (IMDM), containing $10 \%$ heat inactivated fetal bovine serum (FBS) (Lonza) and antibiotics (100 U/ml penicillin and $100 \mu \mathrm{g} / \mathrm{ml}$ streptomycin) (Gibco). Each drugresistant variant was continuously cultured in the presence of the selective drug concentration. All cell lines were maintained at $37^{\circ} \mathrm{C}$ in a humidified $5 \% \mathrm{CO}_{2}$ atmosphere.

Isolation of DXR-resistant clones. DXR-resistant clones were established by continuous exposure of the MG-63 cell line to increasing doses of DXR. Initially, MG-63 cells were cultured in a medium containing $30 \mathrm{ng} / \mathrm{ml}$ DXR up to a concentration of $100 \mathrm{ng} / \mathrm{ml}$. The DXR-resistant cell lines were selected at 30 and $100 \mathrm{ng} / \mathrm{ml}$ and named MG-63DXR30 and MG-63DXR100, respectively. To maintain DXR resistance, MG-63DXR30 and MG-63DXR100 cells were routinely cultured with the appropriate concentration of DXR. From time to time, the sensitivity of cells to DXR was evaluated by the analysis of their resistance to cell death.

In vitro growth characteristics and chemosensitivity. To determine the in vitro growth characteristics of each cell line, cells were seeded in IMDM 10\% FBS in the absence of or with the appropriate concentration of DXR. Cell density and viability were assessed by the erythrosine B (Sigma-Aldrich) dye exclusion method. Doubling time was calculated during the logarithmic phase of growth (from 48 to $96 \mathrm{~h}$ after seeding). Drug sensitivity of each cell line was calculated from the drug

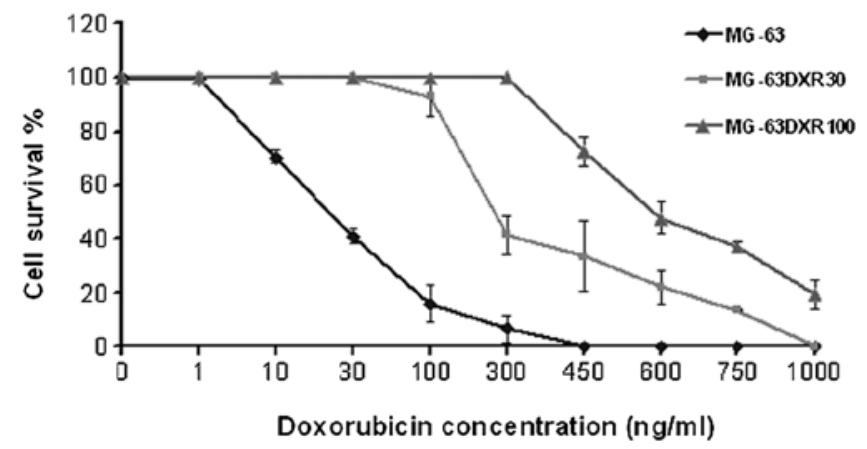

Figure 1. Comparison of the sensitivity to doxorubicin of the MG-63 human osteosarcoma cell line and its DXR-resistant variants. MG-63, MG-63 osteosarcoma parental cell line; MG-63DXR30, MG-63 osteosarcoma cell line resistant to doxorubicin at $30 \mathrm{ng} / \mathrm{ml}$; MG-63DXR100, MG-63 osteosarcoma cell line resistant to doxorubicin at $100 \mathrm{ng} / \mathrm{ml}$. Each point represents the mean \pm SD from three different experiments and is expressed as a percentage of the control.

dose-response curve and expressed as $\mathrm{IC}_{50}$ (drug concentration resulting in 50\% inhibition of cell growth after $72 \mathrm{~h}$ of in vitro treatment). The degree of DXR resistance was expressed as the ratio of the $\mathrm{IC}_{50}$ value of the resistant variant to that of the parental cell line.

Immunoblot analysis. Whole-cell extracts from the parental MG-63 cells and the MG-63DXR30 and MG-63DXR100 resistant variants were analysed by SDS-polyacrylamide gel electrophoresis (PAGE). The protein concentration was quantified by bicinchoninic acid (BCA) (Pierce) protein assay. Primary antibodies used were MDR-1/P-gp, HIF-1 $\alpha$, c-Myc, p21 (Santa Cruz Biotechnology, Santa Cruz, CA, USA) and $\beta$-actin (Sigma-Aldrich). Immunological complexes were visualised by an ECL detection system (Amersham Biosciences, GE Healthcare) and analysed using Quantity One software (Bio-Rad Laboratories, Inc., Hercules, CA, USA).

Statistical analysis. The $\mathrm{IC}_{50}$ value was determined by the linear regression method. All experiments were performed in triplicate, unless otherwise indicated, and data values were presented as means \pm SE. Data were analysed using the Student's t-test; P-values of $\leq 0.05$ were considered to indicate statistical significance $(\mathrm{P}<0.001, \mathrm{P}<0.01, \mathrm{P}<0.05$ are indicated).

\section{Results}

Selection and establishment of DXR-resistant MG-63 sublines . DXR-resistant variants of the MG-63 human osteosarcoma cell line were obtained by initially exposing the parental cell line to $30 \mathrm{ng} / \mathrm{ml}$ DXR. Selection was then continued by stepwise increased DXR concentrations up to $100 \mathrm{ng} / \mathrm{ml}$. Establishment of adequate in vitro growth at each new DXR concentration required $\sim 12-18$ weeks (corresponding to between 8-20 in vitro passages). All the experiments were performed on cell lines maintained in culture for at least 4-6 months after selection with DXR. The established resistant cell lines were selected at 30 and $100 \mathrm{ng} / \mathrm{ml}$ and named MG-63DXR30 and MG-63DXR100, respectively. 
Table I. $\mathrm{IC}_{50}$ values, the increase in the doxorubicin resistance and the doubling time of MG-63 cells and its doxorubicinresistant variants.

\begin{tabular}{lccc}
\hline Cell line & $\begin{array}{c}\mathrm{IC}_{50} \text { values }^{\mathrm{a}} \\
(\mathrm{ng} / \mathrm{ml})\end{array}$ & $\begin{array}{c}\text { Increase in } \\
\text { drug resistance }\end{array}$ & $\begin{array}{c}\text { Doubling } \\
\text { time (h) }\end{array}$ \\
\hline MG-63 & $20 \pm 3.6$ & - & 23.1 \\
MG-63DXR30 & $200 \pm 14.2$ & 10 -fold & 29 \\
MG-63DXR100 & $559 \pm 29$ & 28 -fold & 34.5 \\
\hline
\end{tabular}

${ }^{\mathrm{a}} \mathrm{IC}_{50}$ values after incubation with doxorubicin for $72 \mathrm{~h} .{ }^{\mathrm{b}} \mathrm{The}$ ratio of $\mathrm{IC}_{50}$ for the resistant subline to that of the corresponding parental cell line. MG-63DXR30, MG-63 osteosarcoma cell line resistant to doxorubicin at $30 \mathrm{ng} / \mathrm{ml}$. MG-63DXR100, MG-63 osteosarcoma cell line resistant to doxorubicin at $100 \mathrm{ng} / \mathrm{ml}$. Data are expressed as the means $\pm \mathrm{SD}$ of three different experiments.

In vitro growth characteristics. The $\mathrm{IC}_{50}$ values and the increased resistance to DXR in the selected variants were drawn from the DXR dose-response curve of each cell line (Fig. 1). The increase in DXR resistance compared with that of the parental cell line ranged from 10 -fold for the MG-63DXR30 variant, to 28-fold for the MG-63DXR100 variant (Table I). The analysis of in vitro growth characteristics of the DXR-resistant variants showed that the doubling time of the MG-63DXR30 cells was similar to that of the
MG-63 parental cell line whereas it was significantly longer in the MG-63DXR100 cells (Table I).

Analysis of protein expression. MDR-1/P-gp and HIF-1 $\alpha$ are activated in DXR-resistant MG-63 cells. To evaluate whether the drug-resistance acquired by MG-63 cells is associated with MDR-1/P-gp activation, we examined its expression by western blot analysis. As shown in Fig. 2, a marked induction of this protein was evident in the DXR-resistant cell lines, whereas in the parental MG-63 cell line, MDR-1/P-gp was undetectable. In order to understand the mechanism of drugresistance induced by DXR in this cell line we investigated whether the drug exposure leads to the activation of HIF-1 $\alpha$, known to enhance MDR-1 gene transcription. As shown in Fig. 2, a strong induction of HIF-1 $\alpha$ was noted both in the MG-63DXR30 and MG-63DXR100 cells when compared to that in the parental cell line that did not express this protein. Therefore, the continuous exposure to DXR seems to significantly activate HIF- $1 \alpha$ and consequently MDR-1/P-gp, the responsible factor of drug-resistance development.

HIF-1 $\alpha$ inhibits DXR-mediated apoptosis. It is known that HIF-1 $\alpha$ activity leads to the upregulation or downregulation of target genes that are involved in many aspects of cancer progression, cell proliferation and survival. To better understand the role of HIF- $1 \alpha$ in DXR resistance acquired by MG-63 cells, we analysed the expression of several proteins encoded by HIF-1 $\alpha$ target genes involved in the apoptotic pathways induced by DXR. Using western blot analysis we
$\mathbf{A}$

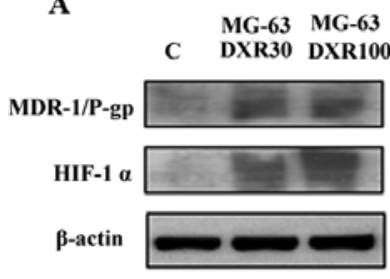

B

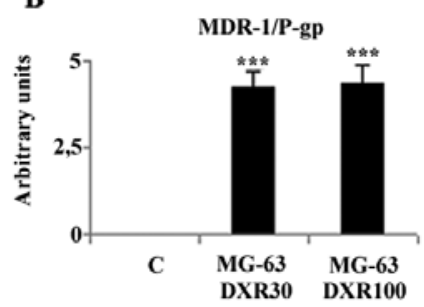

HIF-1 $\alpha$

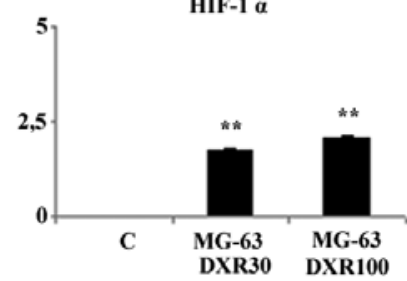

Figure 2. Expression of MDR-1/P-gp and HIF-1 $\alpha$ in parental and DXR-resistant MG-63 cells. (A) Western blot analysis. Lane C, MG-63 osteosarcoma parental cell line; lane MG-63DXR30, MG-63 osteosarcoma cell line resistant to doxorubicin at 30 ng/ml; lane MG-63DXR100, MG-63 osteosarcoma cell line resistant to doxorubicin at $100 \mathrm{ng} / \mathrm{ml}$. $\beta$-actin was used as a protein loading control. (B) Densitometric analysis of the blots expressed as arbitrary units. Each bar represents the mean \pm SD of three experiments. DXR, doxorubicin.

$\mathbf{A}$

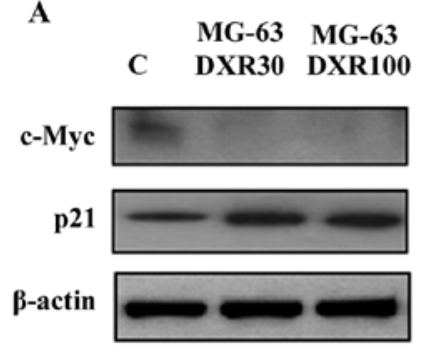

B

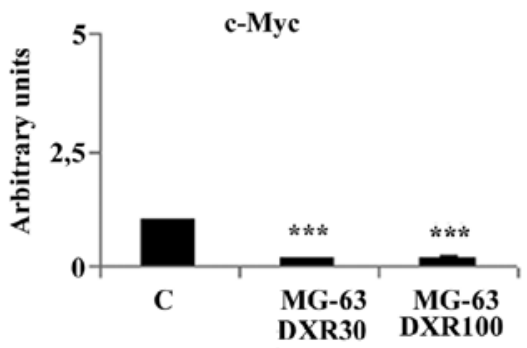

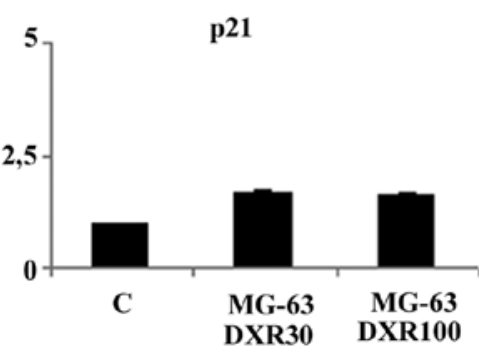

Figure 3. Expression of c-Myc and p21 in the parental and DXR-resistant MG-63 cells. (A) Western blot analysis. Lane C, MG-63 osteosarcoma parental cell line; lane MG-63DXR30, MG-63 osteosarcoma cell line resistant to doxorubicin at $30 \mathrm{ng} / \mathrm{ml}$; lane MG-63DXR100, MG-63 osteosarcoma cell line resistant to doxorubicin at $100 \mathrm{ng} / \mathrm{ml}$. $\beta$-actin was used as a protein loading control. (B) Densitometric analysis of the blots expressed as arbitrary units. Each bar represents the mean \pm SD of three experiments. DXR, doxorubicin. 
A

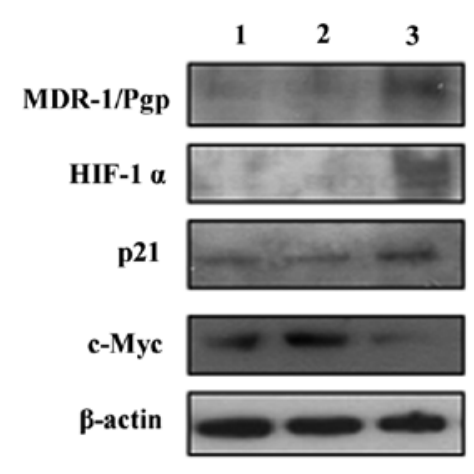

B
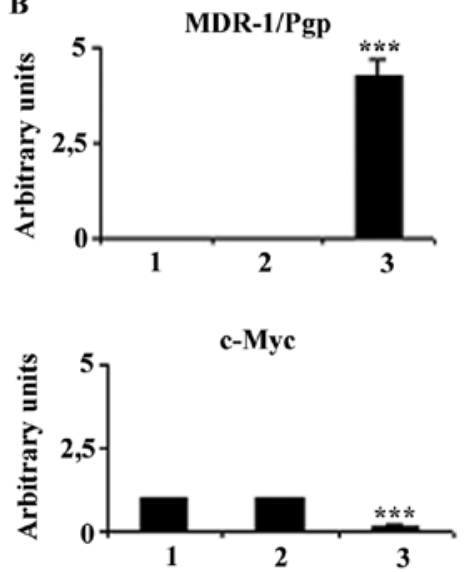

HIF-1 $\alpha$

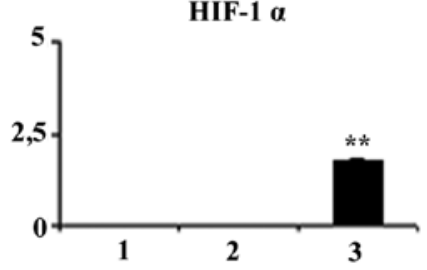

p21

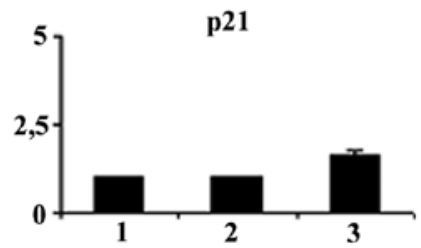

Figure 4. Expression of MDR-1/P-gp, HIF-1 $\alpha$, c-Myc and p21 in DXR-resistant MG-63 cells after continuous culture in DXR-free medium. (A) Western blot analysis. Lane 1, MG-63 human osteosarcoma parental cell line; lane 2, MG-63DXR30 after continuous culture in DXR-free medium; lane 3, MG-63DXR30: MG-63 osteosarcoma cell line resistant to doxorubicin at $30 \mathrm{ng} / \mathrm{ml}$. $\beta$-actin was used as a protein loading control. (B) Densitometric analysis of the blots expressed as arbitrary units. Each bar represents the mean \pm SD of three experiments. DXR, doxorubicin.

observed a significant decrease in the c-Myc expression levels in both DXR-resistant variants when compared to this level in the parental cell line (Fig. 3). Moreover, the downregulation of this protein was accompanied by an increased $\mathrm{p} 21$ protein expression (Fig. 3).

Stability of in vitro DXR resistance. The MG-63 DXR-resistant phenotypes were stable up to 2 months (8-10 in vitro passages) of continuous culture in drug-free medium. After this period, the level of DXR-resistance was significantly decreased with an $\mathrm{IC}_{50}$ value comparable to the MG-63 parental cell line (data not shown). In parallel, the expression of the markers identified and linked to DXR resistance in the MG-63 cells gradually returned to parental-like levels (Fig. 4).

\section{Discussion}

Neoadjuvant chemotherapy with subsequent surgical resection has produced great advancement in osteosarcoma therapy in the last 20 years, with a more favourable prognosis and a nearly $70 \%$ long-term survival rate. However, in certain cases, relapse occurs in initially responsive patients due to the emergence of tumour resistance to anticancer agents $(27,28)$. This phenomenon may be caused by multiple factors including hypoxia (15). In the present study, using human doxorubicinresistant osteosarcoma cells under normoxic conditions, we demonstrated that the development of drug resistance described in this tumour may be related to the activation of HIF- $1 \alpha$, the main factor responsible for the adaptation of a tumour to $\mathrm{O}_{2}$ deficiency. The critical mechanism of drug resistance, both intrinsic and acquired, involves the ABC (ATP-binding cassette) protein transporters P-gp, MRP1 and ABCG2, which pump drug molecules out of cells (7). We first observed that selected doxorubicin-resistant MG-63 cells presented a strong induction of the MDR-1/P-gp protein, thus demonstrating that the resistance developed by these human osteosarcoma cells as a consequence of doxorubicin treatment was mediated by MDR-1 gene activation. This result is in agreement with data indicating that P-gp can detect and bind a large variety of anticancer drugs and other hydrophobic compounds, including anthracyclines such as daunorubin, epirubicin, mitoxantrone and doxorubicin (29). This drug binding activity results in the activation of one of the P-gp ATP binding domains and subsequent hydrolysis of ATP, leading to a major change in the shape of P-gp, which causes extrusion of the drug from the cancer cell (30).

Subsequently, we also observed that doxorubicin-resistant MG-63 osteosarcoma cells obtained and maintained in normoxic conditions showed a significant induction of HIF-1 $\alpha$ expression, which may be caused by its decreased degradation in response to hypoxic stress induced by doxorubicin. Indeed, there are many toxic mechanisms caused by this drug in mammalian tissues, with an increase in free radical formation and in oxidative stress as the most likely (31). Doxorubicin undergoes chemical reduction to a semiquinone radical, which in turn reduces oxygen to a superoxide that may contribute to cytotoxicity (32).

Previous reports showed that an increase in MDR-1/P-gp expression associated with the activation of HIF- $1 \alpha$ in tumour cells may be due to the presence of a functional HIF- $1 \alpha$ binding site (HRE) within the MDR-1 gene promoter (16,22-24). On the basis of these observations, we suggest that doxorubicin, by producing hypoxic stress in MG-63 cells, activates HIF-1 $\alpha$ which in turn induces MDR-1 gene transcription, and consequently the expression of MDR-1/P-gp, responsible for the doxorubicin resistance developed by this cell line.

Previous reports have demonstrated that HIF-1 $\alpha$ not only controls P-gp expression, thus, limiting the drug accumulation within cells, but that it is also able to modify the cellular response to the chemotherapeutic agent, for example by altering drug-induced apoptosis, thus nullifying its healthy effect (33). On the basis of this finding, we analysed the expression of molecules involved in the apoptotic pathways mediated by doxorubicin, and observed a significant downregulation of c-Myc in parallel with an increase in p21 protein expression in both doxorubicin-resistant clones. c-Myc is a transcription factor with a dual capacity, as it is involved both in cellular death and in cell proliferation, and is known to be required 
for the induction of apoptosis by doxorubicin (34). The c-Myc downregulation in doxorubicin-resistant MG-63 cells together with MDR-1/P-gp overexpression suggest an inverse correlation between the two proteins in human osteosarcoma, as already described for N-Myc and MDR-1 in neuroblastoma (35) and for c-Myc and MDR-1 in rhabdomyosarcoma (36). Importantly, HIF-1 $\alpha$ has recently been found to repress the activity of various molecules, including c-Myc, by an innovative HRE-independent mechanism that does not require DNA binding activity (37,38). Moreover, Hayashi et al (39) demonstrated a non-canonical mechanism of action of HIF-1 $\alpha$ that counteracts c-Myc effects on gene expression. In the present study, the HIF-1 $\alpha$-c-Myc pathway was shown to play a role in mediating drug resistance of human osteosarcoma cells. Therefore, our results are consistent with the study of Hayashi et al, which identified the escape from apoptosis driven by the HIF-1 $\alpha$-c-Myc pathway among the mechanisms of malignant progression in tumourigenesis.

In addition, several regulators of the cell cycle, notably p15, p18, p27, p57 and p21, are targets for repression by c-Myc $(40,41)$ and the increase in p21 expression levels that we observed in the doxorubicin-resistant MG-63 cells may be explained by the lack of c-Myc inhibitory activity on its promoter. Although p21 was initially thought to be an inhibitor of cell cycle progression, other studies have suggested that this protein might also be a positive modulator of cell survival and cell cycle progression and may protect various types of cells from death following anticancer treatments $(42,43)$. In particular, this pro-survival activity has been observed in breast adenocarcinoma cells treated with chemotherapeutic agents such as taxol, where high levels of p21 appeared to be correlated with enhanced survival and chemoresistance (44). Furthermore, high levels of p21 have also been associated with drug resistance in acute myelogenous leukaemia, head and neck carcinomas, and colon carcinoma (45-47). Moreover, in many late-stage glioblastomas, known to be extraordinarily resistant to chemotherapy and radiation $(48,49)$, resistance to apoptosis has been linked to elevated p21 levels $(50,51)$. Altogether, these data support a positive role for $\mathrm{p} 21$ in tumour cell survival; this protein may be induced by chemotherapeutic agents promoting its expression, as observed in our doxorubicin-resistant MG-63 cells.

Lastly, we evaluated whether or not the doxorubicinresistant MG-63 cells maintained their acquired resistance with time. After 2 months of continuous culture in drug-free medium these cells lost their resistance and became sensitive to the doxorubicin cytotoxic activity similar to the MG-63 parental cell line. Likewise, we observed that the HIF-1 $\alpha$, MDR-1/P-gp, c-Myc and p21 expression returned to parental cell-like levels. The cells no longer exposed to the drug appeared to gradually return to a basal condition, where HIF-1 $\alpha$ is degraded by the ubiquitine-proteasome system, thus confirming the role of doxorubicin in the induction of its expression in tumour cells.

In conclusion, we suggest a key role for HIF-1 $\alpha$ in MDR development in human osteosarcoma MG-63 cell lines. On the one hand, it facilitates the outward transport of intracellular doxorubicin by expressing P-glycoprotein; on the other hand, it contrasts the apoptotic drug effect by downregulating c-Myc and consequently inducing p21 overexpression. This may be considered a new model of chemo-resistance in human osteosarcoma involving two different pathways of HIF-1 $\alpha$ and may provide an experimental basis for clinical applications in the field of MDR in human osteosarcoma.

\section{Acknowledgements}

The present study was supported by grants from the Italian Association for the Cancer Research (grant no. 11426 to Professor N.B.) and the Italian Ministry of Health, Financial Support for Scientific Research '5 per mille’ 2010.

\section{References}

1. Heare T, Hensley MA and Dell'Orfano S: Bone tumors: osteosarcoma and Ewing's sarcoma. Curr Opin Pediatr 21: 365-372, 2009.

2. Mankin HJ, Hornicek FJ, Rosenberg AE, Harmon DC and Gebhardt MC: Survival data for 648 patients with osteosarcoma treated at one institution. Clin Orthop Relat Res 429: 286-291, 2004.

3. Bacci G, Briccoli A, Rocca M, Ferrari S, Donati D, Longhi A, Bertoni F, Bacchini P, Giacomini S, Forni C, Manfrini M and Galletti S: Neoadjuvant chemotherapy for osteosarcoma of the extremities with metastases at presentation: recent experience at the Rizzoli Institute in 57 patients treated with cisplatin, doxorubicin, and a high dose of methotrexate and ifosfamide. Ann Oncol 14: 1126-1134, 2003.

4. Lewis IJ, Nooij MA, Whelan J, Sydes MR, Grimer R, Hogendoorn PC, Memon MA, Weeden S, Uscinska BM, van Glabbeke M, Kirkpatrick A, Hauben EI, Craft AW and Taminiau AH; MRC BO06 and EORTC 80931 collaborators; European Osteosarcoma Intergroup: Improvement in histologic response but not survival in osteosarcoma patients treated with intensified chemotherapy: a randomized phase III trial of the European Osteosarcoma Intergroup. J Natl Cancer Inst 99: 112-128, 2007.

5. Baldini N, Scotlandi K, Barbanti-Bròdano G, Manara MC, Maurici D, Bacci G, Bertoni F, Picci P, Sottili S, Campanacci M and Serra M: Expression of P-glycoprotein in high-grade osteosarcomas in relation to clinical outcome. N Engl J Med 333: 1380-1385, 1995.

6. Bielack SS, Carrle D, Hardes J, Schuck and Paulussen M: Bone tumors in adolescents and young adults. Curr Treat Options Oncol 9: 67-80, 2008.

7. Gottesman MM, Fojo T and Bates SE: Multidrug resistance in cancer: role of ATP-dependent transporters. Nat Rev Cancer 2: 48-58, 2002.

8. Borst $\mathrm{P}$ and Elferink RO: Mammalian ABC transporters in health and disease. Annu Rev Biochem 71: 537-592, 2002.

9. Ambudkar SV, Kimchi-Sarfaty C, Sauna ZE and Gottesman MM: P-glycoprotein: from genomics to mechanism. Oncogene 22: 7468-7485, 2003.

10. Baldini N, Scotlandi K, Serra M, Picci P, Bacci G, Sottili S and Campanacci M: P-glycoprotein expression in osteosarcoma: a basis for risk-adapted adjuvant chemotherapy. J Orthop Res 17: 629-632, 1999.

11. Harguindey S, Orive G, Luis Pedraz J, Paradiso A and Reshkin SJ: The role of $\mathrm{pH}$ dynamics and the $\mathrm{Na}^{+} / \mathrm{H}^{+}$antiporter in the etiopathogenesis and treatment of cancer. Two faces of the same coin - one single nature. Biochim Biophys Acta 1756: 1-24, 2005.

12. Shicang Y, Guijun H, Guisheng Q, Yuying L, Guoming W and Ruiling G: Efficacy of chemotherapeutic agents under hypoxic conditions in pulmonary adenocarcinoma multidrug resistant cell line. J Chemother 19: 203-211, 2007.

13. Chen KG and Sikic BI: Molecular pathways: regulation and therapeutic implications of multidrug resistance. Clin Cancer Res 18: 1863-1869, 2012.

14. Cheng GM and To KK: Adverse cell culture conditions mimicking the tumor microenvironment upregulate ABCG2 to mediate multidrug resistance and a more malignant phenotype. ISRN Oncol 2012: 746025, 2012. doi:10.5402/2012/746025.

15. Rohwer $\mathrm{N}$ and Cramer T: Hypoxia-mediated drug resistance: novel insights on the functional interaction of HIFs and cell death pathways. Drug Resist Updat 14: 191-201, 2011. 
16. Semenza GL: Hypoxia-inducible factors: mediators of cancer progression and targets for cancer therapy. Trends Pharmacol Sci 33: 207-214, 2012.

17. El Naggar A, Clarkson P, Zhang F, Mathers J, Tognon C and Sorensen PH: Expression and stability of hypoxia inducible factor $1 \alpha$ in osteosarcoma. Pediatr Blood Cancer 59: 1215-1222, 2012.

18. Ke Q and Costa M: Hypoxia-inducible factor-1 (HIF-1). Mol Pharmacol 70: 1469-1480, 2006.

19. Wang GL, Jiang BH, Rue EA and Semenza GL: Hypoxiainducible factor 1 is a basic-helix-loop-helix-PAS heterodimer regulated by cellular $\mathrm{O}_{2}$ tension. Proc Natl Acad Sci USA 92: 5510-5514, 1995.

20. Kallio PJ, Pongratz I, Gradin K, McGuire J and Poellinger L: Activation of hypoxia-inducible factor $1 \alpha$ : posttranscriptional regulation and conformational change by recruitment of the Arnt transcription factor. Proc Natl Acad Sci USA 94: 5667-5672, 1997.

21. Semenza GL: Hypoxia-inducible factor 1: master regulator of $\mathrm{O}_{2}$ homeostasis. Curr Opin Genet Dev 8: 588-594, 1998.

22. Comerford KM, Wallace TJ, Karhausen J, Louis NA, Montalto MC and Colgan SP: Hypoxia-inducible factor-1-dependent regulation of the multidrug resistance $(M D R l)$ gene. Cancer Res 62: 3387-3394, 2002.

23. Chen L, Feng P, Li S, Long D, Cheng J, Lu Y and Zhou D: Effect of hypoxia-inducible factor- $1 \alpha$ silencing on the sensitivity of human brain glioma cells to doxorubicin and etoposide. Neurochem Res 34: 984-990, 2009.

24. Li J, Shi M, Cao Y, Yuan W, Pang T, Li B, Sun Z, Chen L and Zhao RC: Knockdown of hypoxia-inducible factor- $1 \alpha$ in breast carcinoma MCF-7 cells results in reduced tumor growth and increased sensitivity to methotrexate. Biochem Biophys Res Commun 342: 1341-1351, 2006.

25. Liu L, Ning X, Sun L, Zhang H, Shi Y, Guo C, Han S, Liu J, Sun S, Han Z, Wu K and Fan D: Hypoxia-inducible factor-1 $\alpha$ contributes to hypoxia-induced chemoresistance in gastric cancer. Cancer Sci 99: 121-128, 2008.

26. Ding Z, Yang L, Xie X, Xie F, Pan F, Li J, He J and Liang H: Expression and significance of hypoxia-inducible factor-1 alpha and MDR1/P-glycoprotein in human colon carcinoma tissue and cells. J Cancer Res Clin Oncol 136: 1697-1707, 2010.

27. Chi SN, Conklin LS, Qin J, Meyers PA, Huvos AG, Healey JH and Gorlick R: The patterns of relapse in osteosarcoma: the Memorial Sloan-Kettering experience. Pediatr Blood Cancer 42 46-51, 2004.

28. Chou AJ and Gorlick R: Chemotherapy resistance in osteosarcoma: current challenges and future directions. Expert Rev Anticancer Ther 6: 1075-1085, 2006.

29. Saraswathy $M$ and Gong S: Different strategies to overcome multidrug resistance in cancer. Biotechnol Adv 31: 1397-1407, 2013.

30. Gillet JP, Efferth T and Remacle J: Chemotherapy-induced resistance by ATP-binding cassette transporter genes. Biochim Biophys Acta 1775: 237-262, 2007.

31. Yokochi T and Robertson KD: Doxorubicin inhibits DNMT1, resulting in conditional apoptosis. Mol Pharmacol 66: 1415-1420, 2004.

32. Wardman P: Electron transfer and oxidative stress as key factors in the design of drugs selectively active in hypoxia. Curr Med Chem 8: 739-761, 2001.

33. Weidemann A and Johnson RS: Biology of HIF-1 $\alpha$. Cell Death Differ 15: 621-627, 2008

34. Grassilli E, Ballabeni A, Maellaro E, Del Bello B and Helin K Loss of MYC confers resistance to doxorubicin-induced apoptosis by preventing the activation of multiple serine protease- and caspase-mediated pathways. J Biol Chem 279: 21318-21326, 2004.
35. Nakagawara A, Kadomatsu K, Sato S, Kohno K, Takano H, Akazawa K, Nose Y and Kuwano M: Inverse correlation between expression of multidrug resistance gene and $\mathrm{N}-m y c$ oncogene in human neuroblastomas. Cancer Res 50: 3043-3047, 1990.

36. Prados J, Melguizo C, Fernandez A, Aranega AE, Alvarez L and Aranega A: Inverse expression of $m d r l$ and $c-m y c$ genes in rhabdomyosarcoma cell line resistant to actinomycin d. J Pathol 180: 85-89, 1996.

37. Dang CV, Kim JW, Gao P and Yustein J: The interplay between MYC and HIF in cancer. Nat Rev Cancer 8: 51-56, 2008.

38. Yoo YG, Christensen J and Huang LE: HIF-1 $\alpha$ confers aggressive malignant traits on human tumor cells independent of its canonical transcriptional function. Cancer Res 71: 1244-1252, 2011.

39. Hayashi M, Yoo YG, Christensen J and Huang LE: Requirement of evading apoptosis for HIF-1 $\alpha$-induced malignant progression in mouse cells. Cell Cycle 10: 2364-2372, 2011.

40. Wanzel M, Herald S and Eilers M: Transcriptional repression by Myc. Trends Cell Biol 13: 146-150, 2003.

41. Herkert B and Eilers M: Transcriptional repression: the dark side of myc. Genes Cancer 1: 580-586, 2010.

42. Gorospe M, Wang X and Holbrook NJ: Functional role of p21 during the cellular response to stress. Gene Expr 7: 377-385, 1999.

43. Li Y, Dowbenko D and Lasky LA: AKT/PKB phosphorylation of $\mathrm{p} 21^{\mathrm{Cip} / \mathrm{WAF} 1}$ enhances protein stability of $\mathrm{p} 21^{\mathrm{Cip} / \mathrm{WAF} 1}$ and promotes cell survival. J Biol Chem 277: 11352-11361, 2002.

44. Barboule N, Chadebech P, Baldin V, Vidal S and Valette A: Involvement of p21 in mitotic exit after paclitaxel treatment in MCF-7 breast adenocarcinoma cell line. Oncogene 15: 2867-2875, 1997.

45. Zhang W, Kornblau SM, Kobayashi T, Gambel A, Claxton D and Deisseroth AB: High levels of constitutive WAF1/Cip1 protein are associated with chemoresistance in acute myelogenous leukaemia. Clin Cancer Res 1: 1051-1057, 1995.

46. Erber R, Klein W, Andl T, Enders C, Born Al, Conradt C, Bartek J and Bosch FX: Aberrant p21 ${ }^{\mathrm{CIP1} / \mathrm{WAF} 1}$ protein accumulation in head-and-neck cancer. Int J Cancer 74: 383-389, 1997.

47. Wang Y, Blandino G and Givol D: Induced $\mathrm{p} 21^{\text {waf }}$ expression in H1299 cell line promotes cell senescence and protects against cytotoxic effect of radiation and doxorubicin. Oncogene 18: 2643-2649, 1999.

48. Haas-Kogan D, Shalev N, Wong M, Mills G, Yount G and Stokoe D: Protein kinase B (PKB/Akt) activity is elevated in glioblastoma cells due to mutation of the tumor suppressor PTEN/MMAC. Curr Biol 8: 1195-1198, 1998.

49. Wang CC, Liao YP, Mischel PS, Iwamoto KS, Cacalano NA, McBride WH: HDJ-2 as a target for radiosensitization of glioblastoma multiforme cells by the farnesyltransferase inhibitor R115777 and the role of p53/p21 pathway. Cancer Res 66: 6756-6762, 2006.

50. Glaser T, Wagenknecht B and Weller M: Identification of p21 as a target of cycloheximide-mediated facilitation of CD95mediated apoptosis in human malignant glioma cells. Oncogene 20: 4757-4767, 2001

51. Happold C, Roth P, Wick W, Schmidt N, Florea AM, Silginer M, Reifenberger $\mathrm{G}$ and Weller M: Distinct molecular mechanisms of acquired resistance to temozolomide in glioblastoma cells. J Neurochem 122: 444-455, 2012. 